CARDIOVASCULAR MEDICINE

\title{
Five year outcome after primary coronary intervention for acute ST elevation myocardial infarction: results from a single centre experience
}

\author{
G Parodi, G Memisha, R Valenti, M Trapani, A Migliorini, G M Santoro, D Antoniucci
}

Heart 2005;91:1541-1544. doi: 10.1136/hrt.2004.054692

See end of article for authors' affiliations

Correspondence to: Dr Guido Parodi, Division of Cardiology, Careggi Hospital, Viale Morgagni 85,50134 Florence, Italy; parodiguido@libero.it

Accepted 17 January 2005 Published Online First 6 April 2005
Objectives: To analyse the five year outcome of unselected patients with acute myocardial infarction (AMI) treated by primary percutaneous coronary intervention (PCI).

Setting: High volume $\mathrm{PCl}$ tertiary centre.

Design and results: The study was based on a sample of 1009 consecutive patients with ST elevation AMI treated by primary PCI. The mean (SD) clinical follow up was 51 (21) months and the follow up rate was $97.8 \%$. The overall mortality was $20 \%$ and cardiac mortality was $16 \%$. Non-fatal reinfarction rate was $5 \%$ and additional revascularisation procedure rate was 19\%. Hospitalisation for heart failure was needed by 42 patients (4\%). The variables related to mortality in multivariate Cox analysis were age (hazard ratio (HR) 1.054, 95\% confidence interval (Cl) 1.039 to 1.069, p < 0.0001), cardiogenic shock (HR 2.985, $95 \% \mathrm{Cl} 2.157$ to $4.129, \mathrm{p}<0.0001$ ), previous myocardial infarction (HR 1.696, 95\% Cl 1.199 to 2.398, $\mathrm{p}=0.0003$ ), and the presence of multivessel coronary artery disease (HR 1.820,95\% Cl 1.317 to 2.514, $\mathrm{p}=0.0003)$. Each additional high risk feature was associated with a relative risk for five year death of 2.328 (95\% Cl 2.048 to $2.646, p<0.0001$ ).

Conclusions: The satisfactory results of routine mechanical revascularisation strategy in AMI were maintained during several years of follow up. Patients at risk of death during long term follow up may be identified by simple clinical and angiographic characteristics, such as old age, cardiogenic shock, previous myocardial infarction, and multivessel coronary artery disease. The risk of death progressively increases with the number of these high risk features.
$\mathrm{P}$ ercutaneous coronary intervention (PCI) for acute myocardial infarction (AMI) is effective in decreasing mortality and adverse cardiac events. ${ }^{1}$ Information focused on outcomes after primary PCI for AMI has increased in recent years. ${ }^{2}$ However, most reported studies on long term outcome after primary PCI were based on small populations, selected cohorts, or short term follow up. ${ }^{3-9}$

The objective of this study was to analyse the five year clinical outcome of unselected patients with ST elevation AMI treated by primary PCI at a high volume PCI tertiary centre.

\section{METHODS}

\section{Study patients}

From January 1995 a routine policy of primary PCI for patients with ST elevation AMI was adopted at our institution, resulting in the treatment of more than 200 patients with ST elevation AMI a year. The population of the present study is based on 1009 consecutive patients with ST segment elevation AMI referred to our institution, within 12 hours of symptom onset, for emergency primary mechanical revascularisation from January 1995 to August 1999. Patient clinical and angiographic data were prospectively recorded and entered on to the database.

\section{Definitions and outcome measures}

Multivessel coronary artery disease (CAD) was defined as a visually assessed $\geqslant 70 \%$ diameter stenosis of at least one major epicardial artery beyond the infarct related artery. Primary PCI success was defined as the restoration of TIMI (thrombolysis in myocardial infarction) flow grade 3 and a residual minimum stenosis $<30 \%$ at the end of the procedure. Cardiogenic shock was defined as systolic blood pressure $<90 \mathrm{~mm} \mathrm{Hg}$ for $>30$ minutes (without positive inotropic agents or mechanical support) unresponsive to fluid replacement alone that was thought to be secondary to ventricular dysfunction and associated with signs of end organ hypoperfusion such as cold or diaphoretic extremities, altered mental status, or anuria.

All deaths were considered to be of cardiac origin unless a non-cardiac cause was established clinically or at necropsy. Reinfarction was defined as recurrent chest pain or the development of new ECG changes accompanied by a new rise in serum creatine kinase MB concentrations. Additional revascularisation procedures included PCI and coronary artery bypass surgery of the infarct related artery or the other coronary vessels. The diagnosis of heart failure was based on the presence of at least two of the following criteria: dyspnoea, bibasilar pulmonary rales, a third heart sound, or radiographic evidence of pulmonary congestion. After discharge from hospital, patients were referred to their private physician, who regulated treatment. All patients were asked to return to our outpatient clinic for evaluation by one of the investigators six months after discharge and annually thereafter. For those patients not returning to the clinic at the designated time follow up information was collected by telephone interview.

\section{Statistical analysis}

Continuous data are expressed as mean (SD). Baseline data were compared by means of the $\chi^{2}$ test for categorical

Abbreviations: $A M I$, acute myocardial infarction; $C A D$, coronary artery disease; $\mathrm{Cl}$, confidence interval; $\mathrm{HR}$, hazard ratio; $\mathrm{Ml}$, myocardial infarction; $\mathrm{PCl}$, percutaneous coronary intervention; TIMI, thrombolysis in myocardial infarction 
Table 1 Baseline clinical and angiographic characteristics of patients

\begin{tabular}{|c|c|c|c|c|}
\hline & All $(n=1009)$ & $\begin{array}{l}\text { Single vessel CAD } \\
(n=511)\end{array}$ & $\begin{array}{l}\text { Multivessel CAD } \\
(\mathrm{n}=498)\end{array}$ & p Value \\
\hline Age (years) & $63(12)$ & $61(12)$ & $65(12)$ & $<0.0001$ \\
\hline Women & $226(23 \%)$ & $109(22 \%)$ & $117(23 \%)$ & 0.449 \\
\hline Current smoking & $410(41 \%)$ & $252(49 \%)$ & $158(32 \%)$ & $<0.0001$ \\
\hline Hypertension & $335(33 \%)$ & 170 (33\%) & 165 (33\%) & 0.771 \\
\hline Diabetes mellitus & $145(14 \%)$ & $58(11 \%)$ & $87(17 \%)$ & 0.009 \\
\hline Cholesterolaemia $>5.18 \mathrm{mmol} / \mathrm{l}$ & $262(26 \%)$ & $135(26 \%)$ & $127(26 \%)$ & 0.619 \\
\hline Previous MI & $120(12 \%)$ & $30(6 \%)$ & $90(18 \%)$ & $<0.0001$ \\
\hline Previous PCl & $31(3 \%)$ & $12(2 \%)$ & $19(4 \%)$ & 0.01 \\
\hline Previous bypass surgery & 11 (1\%) & $0(0 \%)$ & $11(2 \%)$ & 0.01 \\
\hline Anterior infarction & $525(52 \%)$ & $271(53 \%)$ & $254(51 \%)$ & 0.753 \\
\hline Cardiogenic shock & $127(13 \%)$ & $43(9 \%)$ & $84(17 \%)$ & $<0.0001$ \\
\hline Symptom to balloon time (min) & $190(138)$ & $188(95)$ & $191(149)$ & 0.593 \\
\hline $\begin{array}{l}\text { Chronic occlusion } \\
\text { Infarct related artery }\end{array}$ & $115(11 \%)$ & $0(0 \%)$ & $115(23 \%)$ & $\begin{array}{l}<0.0001 \\
0.001\end{array}$ \\
\hline Left anterior descending & $513(51 \%)$ & $273(53 \%)$ & $240(48 \%)$ & \\
\hline Right coronary & $358(35 \%)$ & $174(34 \%)$ & $184(37 \%)$ & \\
\hline Circumflex & $116(11 \%)$ & $59(11 \%)$ & $57(11 \%)$ & \\
\hline Left main trunk & $11(1 \%)$ & $0(0 \%)$ & $11(2 \%)$ & \\
\hline Venous graft & $6(1 \%)$ & $0(0 \%)$ & $6(1 \%)$ & \\
\hline TIMI flow grade 2-3 & $178(18 \%)$ & $91(18 \%)$ & $87(17 \%)$ & 0.854 \\
\hline
\end{tabular}

variables and unpaired $t$ test for continuous variables. Survival curves were constructed by the Kaplan-Meier method and statistical differences between curves were assessed by the log rank test. Clinical and angiographic variables that were significantly different between survivors and non-survivors in the univariate model, as well as variables known to have prognostic value, were included in the Cox models for all cause mortality and cardiac mortality. A probability value of $\mathrm{p}<0.05$ was considered significant. Data were analysed by SPSS version 11.5 (SPSS Inc, Chicago, Illinois, USA).

\section{RESULTS}

\section{Study population}

Table l summarises baseline clinical and angiographic characteristics of the study patients. Overall, 498 (49\%) patients had multivessel CAD. Patients with multivessel CAD were older and more often had diabetes, a previous myocardial infarction (MI), and previous revascularisation

Table 2 Causes of death during long term follow up

\begin{tabular}{ll}
\hline Cardiac death & $158(78 \%)$ \\
HF & $42(21 \%)$ \\
Cardiogenic shock & $33(17 \%)$ \\
Reinfarction & $22(11 \%)$ \\
Sudden death & $9(4 \%)$ \\
Cardiac rupture & $7(3 \%)$ \\
Cardiac surgery & $6(3 \%)$ \\
Arrhythmias & $2(1 \%)$ \\
Unknown or undetermined & $37(18 \%)$ \\
Non-cardiac death & $45(22 \%)$ \\
Cancer & $23(11 \%)$ \\
Stroke & $8(4 \%)$ \\
Senile marasmus & $4(2 \%)$ \\
Pulmonary embolism & $3(1.5 \%)$ \\
COPD & $1(0.5 \%)$ \\
Aortic aneurysm rupture & $1(0.5 \%)$ \\
Sepsis & $1(0.5 \%)$ \\
Renal insufficiency & $1(0.5 \%)$ \\
Car accident & $1(0.5 \%)$ \\
Bowel infarct & $1(0.5 \%)$ \\
Systemic sclerosis & $1(0.5 \%)$ \\
\hline Data are presented as number (\%) of patients. & \\
COPD, chronic obstructive pulmonary disease; HF, heart failure. \\
\hline
\end{tabular}

procedures (table 1). The incidence of cardiogenic shock on admission was higher in patients with multivessel CAD than in patients with single vessel disease, despite no difference in peak creatine kinase concentrations (2496 (2299) U/l $v 2480$ (2168) $\mathrm{U} / \mathrm{l}, \mathrm{p}=0.964)$.

\section{Procedural results}

Primary PCI success rate was 95\%. Overall, 714 patients $(71 \%)$ had infarct related artery stenting and $184(18 \%)$ had multiple stent implantation. There were no differences in procedural success rate and stent use between patients with single vessel CAD and patients with multivessel CAD (96\% v $94 \%, \mathrm{p}=0.101$, and $74 \% \vee 70 \%, \mathrm{p}=0.156$, respectively). Intra-aortic balloon pump was used in 130 patients (13\%). The routine use of abciximab started in 1998, resulting in the administration of the drug to only $7 \%$ of the study population. Door to balloon time was 22 (15) minutes.

\section{Long term outcome}

Long term clinical follow up data were collected for all but 22 patients (follow up rate $97.8 \%$ ). The mean duration of follow up was 51 (21) months (median 54 months). Overall

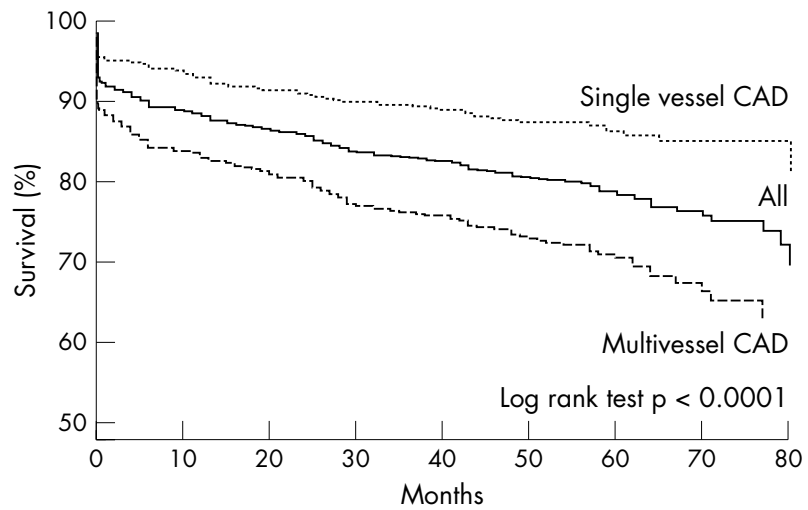

Figure 1 Kaplan-Meier survival curves for patients with single vessel (...) and multivessel coronary artery disease (CAD; - - ), as well as for the overall study population $(-)$. 
Table 3 Predictors of all cause death and cardiac death

\begin{tabular}{lll}
\hline Predictor & HR $(95 \% \mathrm{CI})$ & p Value \\
\hline All cause death & $1.054(1.039$ to 1.069$)$ & $<0.00001$ \\
$\quad$ Age (years) & $2.985(2.157$ to 4.129$)$ & $<0.00001$ \\
$\quad$ Cardiogenic shock & $1.820(1.317$ to 2.514$)$ & 0.0003 \\
$\quad$ Multivessel CAD & $1.696(1.199$ to 2.398$)$ & 0.0003 \\
$\quad$ Previous MI & $1.052(1.035$ to 1.069$)$ & $<0.00001$ \\
Cardiac death & $3.822(2.682$ to 5.445$)$ & $<0.00001$ \\
$\quad$ Age (years) & $2.059(1.404$ to 3.019$)$ & 0.0002 \\
Cardiogenic shock & $1.921(1.317$ to 2.802$)$ & 0.0007 \\
$\quad$ Multivessel CAD & & \\
$\quad$ Previous MI & & \\
\hline Cl, confidence interval; HR, hazard ratio. &
\end{tabular}

mortality was $20 \%$ and cardiac mortality was $16 \%$. Table 2 summarises the causes of death. Of the 203 patients who died, one third $(n=68)$ died within the first 30 days after AMI (mainly in hospital). The remaining deaths occurred homogeneously over the subsequent follow up period. The annual mortality was $10.2 \%$ (6.4\% within the first month) in the first year and $2.8 \%, 3.3 \%, 2.4 \%, 2.7 \%$, and $4.3 \%$ in the subsequent years. Deaths of cardiac origin occurred earlier than non-cardiac deaths (mean time 15 (19) months $v 36$ (24) months, $\mathrm{p}<0.0001)$. Annual cardiac death rate decreased during follow up: $9.3 \% \quad(6.1 \%$ within the first month) in the first year and $2.4 \%, 2.1 \%, 1.5 \%, 1.8 \%$, and $1.0 \%$ in the subsequent five years.

We observed a higher (but not significant) five year mortality among patients with a symptom to balloon time longer than three hours than among patients treated within three hours of symptom onset $(22 \% v 19 \%, \mathrm{p}=0.136$ by $\log$ rank). Moreover, symptom to balloon time was not independently related to long term survival in the multivariate Cox analysis.

Five year mortality was $52 \%, 33 \%$, and $19 \%$ among patients with a final TIMI flow grade $0-1(n=21), 2(n=20)$, and $3(\mathrm{n}=968)$, respectively ( $\mathrm{p}=0.0006$ by log rank).

The non-fatal reinfarction rate was $5 \%$ and the rate of additional revascularisation procedures was 19\%. Forty two patients (4\%) required hospitalisation for heart failure.

Patients with multivessel CAD had higher rates of all cause mortality $(28 \% v 12 \%, \mathrm{p}<0.0001)$, cardiac death $(23 \% v 8 \%$, $\mathrm{p}<0.0001)$, revascularisation procedure $(26 \% \vee 15 \%$, $\mathrm{p}<0.0001)$, and hospitalisation for heart failure $(6 \% \vee 3 \%$, $\mathrm{p}=0.048$ ) than did patients with single vessel disease. Nonfatal reinfarction rates were similar $(6 \% \vee 5 \%, p=0.700)$ between the two groups. Among patients with single vessel $\mathrm{CAD}$, those with an anterior infarct location had a higher five year mortality $(14 \% v 9 \%, \mathrm{p}=0.086)$ and rate of hospitalisation for heart failure $(5 \% v 1 \%, \mathrm{p}=0.041)$ than did patients with an inferior infarct location. Figure 1 depicts long term survival curves for patients with single and multivessel CAD.

One month contrast left ventriculography (available for 779 of 941 eligible patients) showed lower left ventricular ejection fraction in patients who presented with a previous MI at the time of the index infarction than in patients without (48.1 (16.9) $\vee 54.6(12.8), \mathrm{p}=0.0001)$. Five year mortality was $8.6 \%$ and $18.1 \%(\mathrm{p}=0.0001)$ in patients with a left ventricular ejection fraction $\geqslant 0.50$ and $<0.50$ at one month, respectively.

Multivariate Cox analysis identified the variables significantly related to mortality as age, cardiogenic shock, previous MI, and multivessel CAD (table 3).

Table 4 reports clinical event rates in relation to the number of these four high risk features. Each additional high risk feature was associated with a relative risk for five year death of 2.328 (95\% confidence interval 2.048 to 2.646 , $\mathrm{p}<0.0001)$.

\section{DISCUSSION}

This study analysed the longest follow up ever reported of a large series of consecutive, unselected patients with ST elevation AMI treated by primary PCI at a high volume PCI tertiary centre.

One third of the deaths after the primary PCI occurred within the first month (mainly during hospital stay) and were mainly due to cardiogenic shock or refractory heart failure. After the first 30 days, mortality was stable (3-4\% a year), but cardiac deaths decreased over the years, with a parallel increase in non-cardiac deaths.

Age and cardiogenic shock were found to be strong independent predictors of cardiac death after primary PCI, and these figures are consistent with previous reports. ${ }^{7} 810$

The presence of a previous MI emerged as an independent predictor of death. This finding may be explained by the concomitant presence of multivessel CAD or by a lower left ventricular function in these patients.

The presence of multivessel CAD, even if associated with a worse baseline risk profile, was an independent predictor of all cause mortality, as well as of other adverse events. Multivessel CAD is a well known risk factor of patients with AMI undergoing conservative or lytic treatment. ${ }^{11-13}$ This angiographic feature is a marker of severe, diffuse, and more aggressive atherosclerotic CAD and is associated with a poor outcome. Similarly, in their pioneer study Kahn et $a^{14}$ found a relation between the number of diseased vessels and survival after primary angioplasty.

The issue of appropriateness and timing of non-culprit lesion treatment after primary PCI is still debated..$^{14}{ }^{15}$ In this series we used to treat non-culprit lesions in the acute phase in patients with cardiogenic shock or electively with evidence of inducible ischaemia. However, the ischaemia driven strategy could not avoid the poor prognosis of patients with multivessel CAD. Recently, Corpus et al ${ }^{16}$ confirmed that in patients with multivessel CAD and AMI, multivessel PCI is technically feasible but is associated with higher postprocedural morbidity without a benefit in mortality. Whether a treatment strategy guided by vulnerable plaque imaging will provide effective revascularisation has not yet been determined..$^{17}$

Table 4 Gradations of clinical risk and five year outcome

\begin{tabular}{|c|c|c|c|c|c|c|}
\hline & \multicolumn{5}{|c|}{ Number of high risk features } & \multirow[b]{2}{*}{$p$ Value } \\
\hline & $0(n=327)$ & $1(n=342)$ & $2(n=224)$ & $3(n=78)$ & $4(n=16)$ & \\
\hline $\begin{array}{l}\text { Death } \\
\text { Cardiac death } \\
\text { Hospitalisation for HF } \\
\text { Repeat } \mathrm{MI} \\
\text { Additional revascularisation }\end{array}$ & $\begin{array}{l}25(7.6 \%) \\
16(4.9 \%) \\
4(1.2 \%) \\
13(4.0 \%) \\
48(14.7 \%)\end{array}$ & $\begin{array}{l}47(13.7 \%) \\
31(9.1 \%) \\
13(3.8 \%) \\
18(5.3 \%) \\
74(21.6 \%)\end{array}$ & $\begin{array}{l}69(30.8 \%) \\
55(24.6 \%) \\
16(7.1 \%) \\
17(7.6 \%) \\
50(22.3 \%)\end{array}$ & $\begin{array}{l}49(62.8 \%) \\
43(55.1 \%) \\
7(9.0 \%) \\
1(1.3 \%) \\
14(17.5 \%)\end{array}$ & $\begin{array}{l}13(81.3 \%) \\
13(81.3 \%) \\
2(12.5 \%) \\
1(6.3 \%) \\
2(12.5 \%)\end{array}$ & $\begin{array}{l}<0.0001 \\
<0.0001 \\
<0.0001 \\
0.173 \\
0.085\end{array}$ \\
\hline
\end{tabular}


Patients with one or more of the aforementioned high risk features (age $>70$ years, cardiogenic shock, previous MI, and multivessel CAD) had a higher incidence of death and hospitalisation for heart failure in the subsequent five years than did patients without. Moreover, the risk of long term mortality and rehospitalisation progressively rose with the increase in the number of high risk features. However, reinfarction and additional revascularisation rates cannot be predicted just by the number of these high risk characteristics. In patients without high risk features a good five year outcome, with low rates of major adverse events, can be expected.

In a previous randomised trial based on 395 selected patients with AMI, primary coronary angioplasty resulted in lower five year mortality $(13 \% v 24 \%, \mathrm{p}=0.01)$ and rate of non-fatal reinfarction $(6 \% \vee 22 \%, \mathrm{p}<0.01)$ than did thrombolytic treatment with streptokinase. ${ }^{5}$ However, the exclusion from random selection of patients with pronounced haemodynamic instability or ECG signs of extensive infarction prevents comparison of this trial population with our patient series. Mahon et al, ${ }^{18}$ analysing the long term outcome of 1059 consecutive patients with AMI admitted to a tertiary centre in the thrombolytic era, found a five year survival of $50 \%$. In this "real world" analysis only $28 \%$ of the patients included in the study received thrombolysis and 32\% had predischarge coronary angiography.

In our primary PCI series, symptom to balloon time was not independently related to five year survival in the multivariate Cox analysis. This finding confirms that time is less important when mechanical reperfusion is used than with a pharmacological reperfusion strategy. ${ }^{19}$

\section{Conclusions}

The satisfactory results of a routine mechanical revascularisation strategy in AMI were maintained during several years of follow up. Patients at risk of death during long term follow up may be identified by simple clinical and angiographic characteristics, such as old age, cardiogenic shock, previous MI, and multivessel CAD. The risk of death progressively increases with the number of these high risk features.

\section{Authors' affiliations}

G Parodi, G Memisha, R Valenti, M Trapani, A Migliorini, G M Santoro, D Antoniucci, Division of Cardiology, Careggi Hospital, Florence, Italy This study was supported by the ARCARD Foundation, Florence, Italy.

\section{REFERENCES}

1 Montalescot G, Andersen HR, Antoniucci D, et al. Recommendations on percutaneous coronary intervention for the reperfusion of acute ST elevation myocardial infarction. Heart 2004;90:e37.

2 Brodie BR, Grines CL, Ivanhoe R, et al. Six-month clinical and angiographic follow-up after direct angioplasty for AMI: final results from the primary angioplasty registry. Circulation 1994;90:156-62.

3 Nunn CM, O'Neill WW, Rothbaum D, et al. Long-term outcome after primary angioplasty: report from the primary angioplasty in myocardial infarction (PAMI-I) trial. $J$ Am Coll Cardiol 1999:33:640-6.

4 O'Keefe J, Rutherford B, McCohany D, et al. Early and late results of coronary angioplasty without antecedent thrombolytic therapy for acute myocardial infarction. Am J Cardiol 1989;64:1221-30.

5 Zijlstra F, Hoorntje JCA, de Boer M, et al. Long-term benefit of primary angioplasty as compared with thrombolytic therapy for acute myocardial infarction. N Engl J Med 1999:341:1413-9.

6 Waldecker B, Waas W, Haberbosch W, et al. Long-term follow-up after direct percutaneous transluminal coronary angioplasty for acute myocardial infarction. J Am Coll Cardiol 1998;32:1320-5.

7 Beohar N, Davidson CJ, Weigold G, et al. Predictors of long-term outcomes following direct percutaneous coronary intervention for acute myocardial infarction. Am J Cardiol 2001;88:1103-7.

8 Hannan EL, Racz MJ, Arani DT, et al. Short- and long-term mortality for patients undergoing primary angioplasty for acute myocardial infarction. J Am Coll Cardiol 2000;36:1194-201.

9 Shihara M, Tsutsui H, Tsuchihashi M, for the Japanese Coronary Intervention Study (JCIS) Group, et al. In-hospital and one-year outcome for patients undergoing percutaneous coronary intervention for acute myocardial infarction. Am J Cardiol 2002;90:932-6.

10 Hochman JS, Slepper LA, Webb JC, et al. Early revascularization in acute myocardial infarction complicated by cardiogenic shock. N Engl J Med 1999;341:625-34

11 Sanz G, Castaner A, Betriu A, et al. Determinants of prognosis in survivors of acute myocardial infarction: a prospective clinical angiographic study. N Engl J Med 1982;306:1065-70.

12 Simoons ML, Vos J, Tijssen JG, et al. Long-term benefit of early thrombolytic therapy in patients with acute myocardial infarction: 5 year follow-up of a trial conducted by the Interuniversity Cardiology Institute of the Netherlands. J Am Coll Cardiol 1989;14:1609-15.

13 Arnold AE, Simoons ML, Detry JM, et al. Prediction of mortality following hospital discharge after thrombolysis for acute myocardial infarction: is there a need for coronary angiography? European Cooperative Study Group. Eur Heart J 1993;14:306-15.

14 Kahn JK, Rutherford BD, McConahay DR, et al. Results of primary angioplasty for acute myocardial infarction in patients with multivessel coronary artery disease. J Am Coll Cardiol 1990;16:1089-96.

15 Telayna JM, Lev GA, Valdivieso L, et al. Percutaneous interventional approach in acute myocardial infarction: treatment of culprit lesion versus complete revascularization. Am J Cardiol 2002;90:47-8H

16 Corpus RA, House JA, Marso SP, et al. Multivessel percutaneous coronary intervention in patients with multivessel disease and acute myocardial infarction. Am Heart J 2004; 148:493-500.

17 Naghavi $M$, Libby $P$, Falk E, et al. From vulnerable plaque to vulnerable patient: fa call for new definition and risk assessment strategies. Part II. Circulation 2003;108:1772-8.

18 Mahon NG, O'Rorke C, Codd MB, et al. Hospital mortality of acute myocardial infarction in the thrombolytic era. Heart 1999;81:478-82.

19 Schömig A, Ndrepepa G, Mehilli J, et al. Therapy-dependent influence of time-to-treatment interval on myocardial salvage in patients with acute myocardial infarction treated with coronary stenting or thrombolysis. Circulation 2003;108:1084-8.

\section{1 th European Forum on Quality Improvement in Health Care}

26-28 April 2006, Prague, Czech Republic

For further information please go to: www.quality.bmipg.com

Book early to benefit from a discounted delegate rate 